its use in many countries, where it cannot be easily obtained. In France it is produced in kits containing $4 \mathrm{~g}$ hydroxocobalamin to be diluted in sodium thiosulphate (the cost of a kit is about 800 French francs). We give $4 \mathrm{~g}$ intravenously in $80 \mathrm{ml} 10 \%$ sodium thiosulphate over three to five minutes. This can be repeated several times if necessary.

Great emphasis should be given to the need to undertake supportive measures concomitantly with the administration of antidotes and chelating agents. The symptomatic treatment of a pulmonary oedema, a cardiac arrhythmia, or an acidosis is always an emergency.

In our experience, when these treatments are rapidly applied the prognosis of massive cyanide poisoning is markedly improved: all the 24 patients we have treated in our unit made a complete recovery.

R GARNIER

C BISMUTH

G Riboulet-Delmas M-L EFTHYMIOU

Poisons Unit,

Hôpital Fernand Widal,

75010 Paris,

France

\section{Interaction between diuretics and} indomethacin

SIR,-A recent report by Drs A C Yeung Laiwah and R A MacTier (12 September, p 714) highlighted the antagonistic action of ibuprofen and naproxen against frusemide. Indomethacin, another such non-steroidal anti-inflammatory agent, has been shown to antagonise the diuretic action of frusemide in animal experiments ${ }^{12}$ and in healthy volunteers. ${ }^{3}$ It is recognised that indomethacin may cause fluid retention, thus exacerbating cardiac failure. We therefore report details of a patient illustrating the interaction of indomethacin and diuretic therapy in severe cardiac failure.

A 63-year-old postman was admitted with severe congestive cardiac failure developing over several months despite treatment with digoxin and diuretics. He had previously suffered two myocardial infarctions. On examination he was breathless at rest, had controlled atrial fibrillation, a blood pressure of $120 / 85 \mathrm{~mm} \mathrm{Hg}$, jugular venous pressure raised to $5 \mathrm{~cm}$, and pulmonary and leg oedema. Initial management comprised bed rest, digoxin, frusemide, spironolactone, isosorbide dinitrate, and allopurinol. He developed acute gout when indomethacin, $50 \mathrm{mg}$ four times a day, was prescribed. The clinical signs of cardiac failure increased, with development of tricuspid incompetence and anasarca. The dose of frusemide was increased to $250 \mathrm{mg}$ three times a day and intravenous bumetanide, $6 \mathrm{mg}$ daily, was added with little improvement. The indomethacin was replaced by flurbiprofen, $50 \mathrm{mg}$ three times daily. A brisk diuresis began the following day, with a loss of 10 litres in 48 hours. The cardiac failure resolved rapidly in the next few days. There was no other change in therapy and the diuresis represented a loss of $9 \mathrm{~kg}$ in four days. On discharge the patient had good exercise tolerance and was free from peripheral oedema.

Our patient's cardiac failure showed sudden improvement after indomethacin was replaced by flurbiprofen. There was a dramatic diuresis, which resulted in control of his intractable cardiac failure. The antidiuretic activity of indomethacin has been well documented, mainly in animal experiments; but clinically important interactions of this nature do not seem widely recognised. The role of prostaglandins in the kidney remains difficult to interpret, ${ }^{4}$ but it is tempting to suppose that the interaction of prostaglandin synthetase inhibitors, such as indomethacin, with diuretics is intimately associated with prostaglandin activity in the kidney. It is puzzling that the substitution of flurbiprofen, a potent prostaglandin synthetase inhibitor, did not continue to antagonise the diuretics, though the relative dosage may represent a reduction in antagonist activity. Further reduction in the dose of diuretics was possible when the flurbiprofen dose was reduced.

As both non-steroidal anti-inflammatory drugs and diuretics are widely prescribed, often in combination, the interaction of these drugs may prove to be more important than is currently recognised.

Simon G Allan

Infection Unit,

City Hospital,
Aberdeen AB2 1NJ

J KNox

Raigmore Hospital,
Inverness

F KERR

1 Oli E, Kover G, Larsson C, Anggard E. Eur $\mathcal{f}$ Pharmacol 1976;38:95-100

${ }^{2}$ Olsen WB. Acta Pharmacol Toxicol 1975;37:65-78.

- Anonymous. Lancet 1981 ;ii:343-5.

\section{Synergistic action of metolazone and frusemide}

SIR,-The management of patients with gross oedema who are resistant to large doses of "loop" diuretics is difficult. A synergistic action between metolazone and frusemide is well recognised in this situation, ${ }^{1}$ but can result in massive diuresis, with serious electrolyte disturbances and volume depletion. For these reasons Drs R R Ghose and S K Gupta (2 May, $p$ 1432) recommended adding half the lowest starting dose of metolazone - that is, $2.5 \mathrm{mg}$; their patients, however, were not on particularly large doses of "loop" diuretics. Dr Janet M Allen and others (6 June, p 1873) suggested halving the dose of the loop diuretic before starting metolazone, but $\mathrm{Dr} J \mathbf{M}$ Bamford (29 August, p 618) found that this does not prevent an uncontrolled diuresis. We have found that reducing the dose of metolazone to $1.25 \mathrm{mg}$ also does not avoid an uncontrolled diuresis.

A 24-year-old woman with nephrotic syndrome was admitted to the metabolic ward because she had gross oedema and continued to gain weight despite being on frusemide $500 \mathrm{mg} /$ day and amiloride $10 \mathrm{mg} /$ day. She was given $5 \mathrm{mg}$ metolazone while continuing on the $500 \mathrm{mg}$ frusemide/ day. Over the next 24 hours she had a massive diuresis (table). The metolazone was therefore discontinued, but two days later, because of no further weight loss, she was given $2.5 \mathrm{mg}$ metolazone, which caused a further massive diuresis (table). The metolazone was again stopped, since she had developed severe postural hypotension and felt very unwell. Two weeks later she was readmitted, since her weight had again increased despite the large dose of frusemide. Because of the previous experience she was given only $1.25 \mathrm{mg}$ metolazone; once more she had a massive diuresis (table) and again had severe postural hypotension, being unable to get out of bed, despite still being oedematous.

The mechanism of the synergism between metolazone and loop diuretics is not understood, but it would appear that only a very small dose of metolazone is needed to produce a massive diuresis, which could be extremely dangerous if there is not careful observation. It would appear that much smaller doses of metolazone than $1.25 \mathrm{mg}$ should be used in this situation if the diuresis is to be more
Changes in the first 24 hours following administration of $5,2 \cdot 5$, and $1 \cdot 25 \mathrm{mg}$ of metolazone to "frusemideresistant" patient with nephrotic syndrome on $500 \mathrm{mg}$ of frusemide

\begin{tabular}{lrrr}
\hline & \multicolumn{3}{c}{ Dose of metolazone (mg) } \\
\cline { 2 - 4 } & \multicolumn{1}{c}{5} & 2.5 & $1 \cdot 25$ \\
\hline Sodium loss (mmol (mEq)/ & & & \\
24 h) & 549 & 457 & 358 \\
Urine volume (1/24 h) & 4.9 & 4.5 & 3.3 \\
Weight loss $(\mathrm{kg})$ & 2.5 & 2.6 & $2 \cdot 0$ \\
\hline
\end{tabular}

controlled. At present this can only be done by grinding and weighing out $5 \mathrm{mg}$ tablets (the smallest available); perhaps the manufacturer (Hoechst) should consider making smaller tablets available, so that a controlled diuresis could then be obtained. However, the initial dose remains to be determined.

EDWINA BROWN Graham MACGREgor

Department of Medicine, Charing Cross Hospital Medical School,
London W6 8RF

${ }^{1}$ Asscher AW. Clin Trials $\mathcal{f} 1974 ; 4: 134-7$.

\section{Opiate toxicity in elderly patients}

SIR,-I note with interest Dr R C Gupta's comment (31 October, p 1191) on Dr T H Caradoc-Davies's article (3 October, p 905) on opiate toxicity in the elderly. His suggestion is that perhaps buprenorphine can be used as an alternative analgesic in patients who are oversensitive to morphine.

I would like to point out that the unwanted effects of buprenorphine are similar to those of other narcotic analgesics; and that respiratory depression from over dosage cannot be treated with naloxone and requires either assisted ventilation or, according to the manufacturer's recommendation, intravenous dexapram, a selective respiratory stimulant (by injection or infusion). ${ }^{1}$ The peak effect of buprenorphine on respiration, according to the manufacturer's technical brochure, has been found to occur later and last longer than that of morphine. In particular, caution should be taken in patients with impaired respiratory function and any other concomitant liver disease as buprenorphine is metabolised in the liver.

J Hossain

Orpington Hospital,

Orpington, Kent

${ }^{1}$ Anonymous. Drug Ther Bull 1979;March 2:17.

\section{Growth failure}

SIR,-With reference to Dr H B Valman's article on growth failure (5 September, p 655), many children with treatable causes of extreme short stature are referred for investigation so late that appropriate therapy can no longer ensure a final height within the normal range." Among the commonest causes are "idiopathic" growth hormone deficiency, with a predicted incidence of one in $5000,{ }^{2}$ and hypothyroidism, the incidence of which in the childhood population is not known but may be about half this. ${ }^{3}$

One way of detecting these children at an earlier age is to reinstitute the routine measurement of height of all children at entry to primary school. In the majority of the country this was dropped from the school medical examination 